\title{
DESSULFURIZAÇÃO DO GÁS NATURAL POR ADSORÇÃO COM CARBONOS ATIVADOS MODIFICADOS
}

\author{
M. F. AGUIAR ${ }^{1}$, A. C. P. GUIMARÃES ${ }^{1}$ e G. L. V. COELHO ${ }^{1}$ \\ ${ }^{1}$ Universidade Federal Rural do Rio de Janeiro, Departamento de Engenharia Química \\ E-mail para contato: coelho@ufrrj.br
}

\begin{abstract}
RESUMO - Combustível fóssil importante para geração de energia em indústrias e outros setores, o gás natural necessita de procedimentos para remoção de impurezas, como compostos sulfurados, de sua composição. Um método de dessulfurização é o processo de adsorção, sendo o carbono ativado amplamente empregado. Neste estudo, através de curvas de ruptura, o comportamento de um carbono ativado granular modificado por impregnação com cloreto de ferro III e por oxidação com ácido nítrico frente a sete compostos de enxofre presentes em uma amostra de gás natural sintetizada foi avaliado. Os dois métodos de modificação melhoraram a capacidade de adsorção. Após a impregnação com ferro, o composto que obteve maior aumento da capacidade de adsorção foi o tercbutilmercaptana (TBM), e com o carbono ativado oxidado pelo $\mathrm{HNO}_{3}$ foi o metiletilsulfeto (DMS).
\end{abstract}

\section{INTRODUÇÃO}

Com diversas aplicações na indústria e outros setores, o gás natural é uma importante fonte de energia, além de ser a principal matéria-prima em vários segmentos da indústria química. Entretanto, problemas como o envenenamento de catalisadores, corrosão de equipamentos e entre outros, podem advir de compostos organosulfurados presentes na composição desse combustível fóssil (Malvesti et al., 2009).

Com a gradativa necessidade de emissões mais limpas por parte dos órgãos ambientais, novas tecnologias tendo em vista à remoção adicional de enxofre mediante processos de adsorção vêm sendo estudadas. Uma técnica promissora, menos complexa e de alta eficiência, porém o adsorvente utilizado necessita ter elevada área superficial e propriedades texturais que contribuam no desempenho cinético e de equilíbrio de adsorção (Ruthven,1984). O carbono ativado é um dos principais adsorventes empregados em processos adsortivos devido a sua estrutura de poros bem desenvolvida, área superficial e dos grupos funcionais em sua superfície (Cooney, 1999).

Estudos recentes analisam métodos de modificação para adaptar e alterar propriedades físicas e químicas na superfície do carbono ativado. Segundo Cui e colaboradores (2008), resultados superiores são obtidos provenientes da modificação de adsorventes. Quer por oxidação, geralmente com um ácido forte, sulfúrico ou nítrico ou por impregnação com cloreto de ferro III. Tais alterações adicionam mais grupos ácidos à superfície e formam locais de adsorção ativos na superfície do carbono, respectivamente, favorecendo reações de oxidação/adsorção. 
Sendo assim, duas modificações por impregnação com cloreto de ferro III e por oxidação usando ácido nítrico foram realizadas na superfície do carbono ativado, a fim de melhorar sua capacidade de adsorção em relação aos sete compostos sulfurados identificados em uma amostra de gás natural sintética.

\section{MATERIAIS E MÉTODOS}

\subsection{Materiais}

Os experimentos foram realizados com uma amostra sintética de gás natural contendo nove compostos sulfurados confeccionada pela empresa White Martins. Um carbono ativado da casca de côco (CD 500, Carbonmar Com. e Serviços de Carvão Ativado LDTA) foi utilizado como material de origem em todas as amostras modificadas por impregnação ou oxidação.

\subsection{Métodos}

Preparo da Amostra: Inicialmente, a amostra de carbono ativado original foi fragmentada em um triturador A-10 Analytical Mill, marca TEKMAR por 5 minutos. Em seguida, peneiras da série Tyler (W.S. Tyler, USA) foram utilizadas a fim de obter amostras granulometricamente homogêneas.

Isotermas de Adsorção de $\mathrm{N}_{2}$ : A caracterização textural dos carbonos ativados com e sem modificação foi realizada pelo método de adsorção/dessorção de nitrogênio a $77 \mathrm{~K}$. A análise foi realizada no equipamento ASAP 2020, marca Micromeritics, onde cerca de 200 mg de cada amostra foi submetida à desgaseificação sob vácuo, a $300{ }^{\circ} \mathrm{C}$ por $12 \mathrm{~h}$. Após o tratamento térmico, foi obtido o peso seco e, posteriormente, foram submersas em nitrogênio líquido a $77 \mathrm{~K}$ para a aquisição dos pontos experimentais. Os dados de volume de gás adsorvido em função da pressão parcial foram correlacionados por modelos matemáticos. $\mathrm{O}$ método Barret, Joyner e Halenda (BJH) para a obtenção da distribuição do tamanho de poros e, a teoria de Braunner, Emmet e Teller (BET) para cálculo dos valores de área superficial específica do material.

Modificação dos adsorventes: Conforme a metodologia proposta por Cui e colaboradores (2008), impregnou-se o carbono ativado virgem através da imersão em uma solução $0,1 \mathrm{~N}$ de cloreto de ferro III a $80^{\circ} \mathrm{C}$, aproximadamente, por 6 horas, seguido de lavagem, filtração e secagem em estufa. Para a oxidação do carbono ativado virgem, ácido nítrico $(65 \%)$ foi misturado até não haver mais liberação de gás castanho-avermelhado, em seguida a amostra foi também lavada, filtrada à vácuo e seca em estufa.

Adsorção em leito fixo: Um tubo de aço inoxidável de $10 \mathrm{~cm}$ de comprimento e aproximadamente $6,7 \mathrm{~mL}$ de volume foi utilizado como coluna de adsorção, posicionado verticalmente. Inicialmente, uma corrente de $\mathrm{N}_{2}$ ultrapuro percorreu toda unidade experimental com o intuito de remover quaisquer impurezas e em seguida, foi realizado vácuo em toda linha antes de iniciar os experimentos. Todas as curvas de rupturas foram realizadas em temperatura ambiente com $0,03 \mathrm{~g}$ de massa de sorvente, e esferas de vidro foram empacotadas dentro do recipiente, na entrada e na saída da coluna a fim de distribuir 
uniformemente o fluxo. A amostra de gás natural foi alimentada com um fluxo de $5 \mathrm{~mL} / \mathrm{min}$, ascendente na coluna de adsorção e as amostras foram analisadas em um cromatógrafo de fase gasosa (GC) em intervalos de 1 hora.

A alimentação ocorreu até que as concentrações na saída da coluna da maioria dos compostos sulfurados presentes na amostra de gás natural alcançassem um valor próximo à concentração de alimentação (saturação do leito), quando o sistema se aproxima do equilíbrio. Com isso, todas as curvas de rupturas foram realizadas em 5 horas de experimento em fluxo contínuo.

Condições Cromatográficas: As análises de perfil cromatográfico das diferentes amostras foram realizadas em cromatógrafo em fase gasosa equipado com equipado com uma coluna capilar SPB-1 de dimensões $60 \mathrm{~m}$ x $0.32 \mathrm{~mm}$ x $5 \mu \mathrm{m}$ e detector de ionização em chama (FID -Flame Ionization Detector) mantido a $250{ }^{\circ} \mathrm{C}$. A temperatura inicial do forno foi de 35 ${ }^{\circ} \mathrm{C}$ por 5 minutos, em seguida a temperatura foi elevada a $65^{\circ} \mathrm{C}$ com uma rampa de aquecimento de $1{ }^{\circ} \mathrm{C} / \mathrm{min}$. Posteriormente, essa temperatura foi elevada a $160{ }^{\circ} \mathrm{C}$ com uma taxa de aquecimento de $15^{\circ} \mathrm{C} / \mathrm{min}$, permanecendo nessa temperatura final por 5 minutos. $\mathrm{O}$ tempo de corrida total ficou em 46 minutos.

\section{RESULTADOS E DISCUSSÕES}

\subsection{Isotermas de adsorção de Nitrogênio (ASAP)}

A adição de grupos ácidos na superfície do carbono afeta a sua área superficial, volume de poro e diâmetro médio dos poros. Na Tabela 1 está descrita a análise textural BET por meio dela foi possível analisar as alterações dessas propriedades.

Tabela 1 - Características superficiais dos adsorventes

\begin{tabular}{|c|c|c|c|c|}
\hline Adsorvente & $\begin{array}{c}\text { Área BET } \\
\left(\mathrm{m}^{2} \cdot \mathrm{g}^{-1}\right)\end{array}$ & $\begin{array}{c}\text { Área de } \\
\text { microporo } \\
\left(\mathrm{m}^{2} \cdot \mathrm{g}^{-1}\right)\end{array}$ & $\begin{array}{c}\text { Volume de } \\
\text { microporo } \\
\left(\mathrm{cm}^{3} \cdot \mathrm{g}^{-1}\right)\end{array}$ & $\begin{array}{c}\text { Diâmetro } \\
\text { médio dos } \\
\text { poros }(\AA)\end{array}$ \\
\hline \hline $\mathrm{CA}-$ Virgem & 150 & 109 & 0,050 & 24 \\
\hline $\mathrm{CA}-\mathrm{FeCL}_{3}$ & 117 & 89 & 0,041 & 24 \\
\hline $\mathrm{CA}-\mathrm{HNO}_{3}$ & 100 & 76 & 0,035 & 24 \\
\hline
\end{tabular}

Conforme a Tabela 1 verifica-se que os dois métodos de modificação diminuem a área superficial. Sendo que na oxidação com ácido nítrico esse decréscimo foi maior. Resultados análogos foram encontrados por diferentes pesquisadores após as modificações, porém os motivos para que isso ocorra ainda são divergentes. Segundo Zhou e colaboradores (2009) a redução da área superficial ocorre devido à destruição parcial da estrutura dos poros pela oxidação, consequentemente há um decréscimo da capacidade de adsorção após a modificação. Já outros autores afirmam que este comportamento se deve à geração de grupos funcionais adicionados na superfície do adsorvente favorecendo assim a adsorção dos compostos sulfurados (Cui e Turn, 2009; Qiu et al., 2016).

\subsection{Curvas de breakthroug}


De acordo com a Equação 1, a integral da área entre a ordenada e curva de breakthroug resulta na quantidade adsorvida de cada substância, dado que a vazão (Q) é constante e a concentração inicial $\left(\mathrm{C}_{0}\right)$ de cada composto sulfurado na amostra de gás natural é conhecida (Aksu et al., 2007). Dessa forma, a quantidade total de adsorbato removido dividida pela massa total de adsorvente $\left(\mathrm{m}_{\mathrm{CA}}\right)$ na coluna fornece a capacidade de adsorção por grama de adsorvente.

$$
q=\frac{c_{0} Q}{m_{C A}} \int_{0}^{t}\left(1-\frac{c}{c_{0}}\right) d t
$$

As curvas de rupturas para todos os adsorventes utilizados para os setes compostos sulfurados presentes na amostra de gás natural foram realizados, e com o auxílio do software OriginPro 8.5 obteve-se a área abaixo de cada curva. A Figura 1 representa as curvas de rupturas para o tetrahidrotiofeno e o metiletilsulfeto em todos os adsorventes utilizados neste trabalho.

Figura 1 - Curvas de breakthrough para o tetrahidrotiofeno e metiletilsulfeto em todos os adsorventes
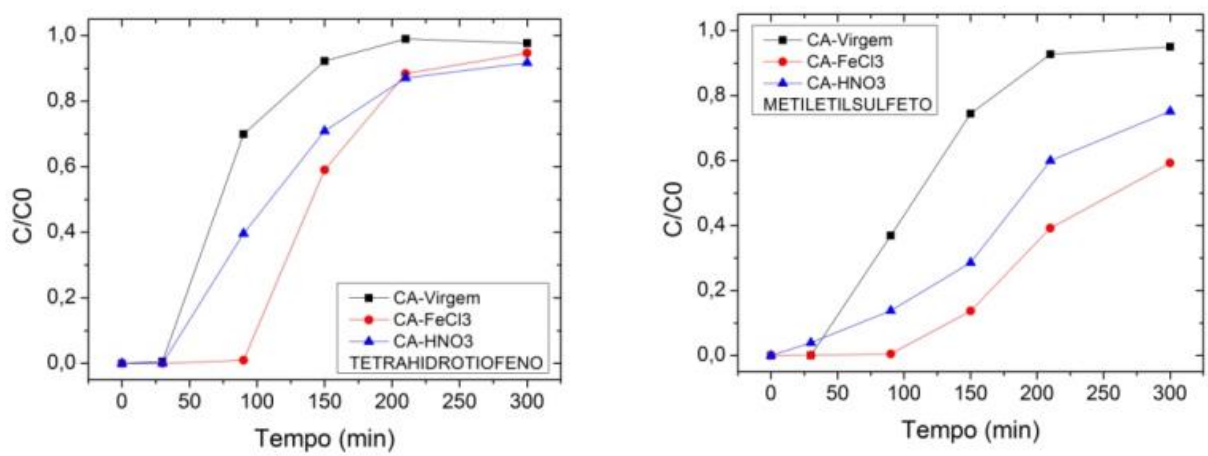

Nota-se pela Figura 1, que ambos os carbonos modificados promoveram o deslocamento dos pontos de ruptura (breakpoint) do tetrahidrotiofeno e do metiletilsulfeto em relação ao adsorvente virgem. Na impregnação com cloreto de ferro III o breakpoint deslocou-se para a direita, isto é, demorou mais tempo para que uma quantidade característica do afluente fosse identificada na saída do leito (Cui et al., 2008). Diferente da modificação por oxidação, em que o ponto de ruptura do $\mathrm{CA}-\mathrm{HNO}_{3}$ ocorre simultaneamente ao do CAvirgem, contudo a quantidade de massa adsorvida nesse ponto não é a mesma nos dois casos, visto que, na saída do leito foi detectada uma massa menor de $\mathrm{CA}-\mathrm{HNO}_{3}$ no mesmo instante. Por consequência, a curva de breakthrough para o $\mathrm{CA}-\mathrm{HNO}_{3}$ ficou deslocada para baixo em relação à curva de ruptura do CA-Virgem, apontando uma maior capacidade de adsorção em razão do tempo até a saturação ser maior.

Logo, ambos os carbonos ativados modificados quando comparados ao adsorvente virgem revelam uma melhor capacidade de adsorção para todos os compostos sulfurados. $\mathrm{O}$ carbono ativado impregnado apresentou a maior capacidade de enxofre total entre os três adsorventes utilizados. A Tabela 2 apresenta as capacidades de adsorção para todos os adsorventes testados considerando um tempo morto de um minuto e 27 segundos equivalente 
a um erro máximo de $1,5 \%$ na capacidade de adsorção para o Sec-butilmercaptana e o Tercbutilmercaptana, já para os demais compostos o erro médio foi de $0,7 \%$.

Tabela 2 - Capacidades de adsorção (mg/g) para os sete compostos sulfurados presente no gás natural sintético em todos os adsorventes

\begin{tabular}{|c|c|c|c|c|c|c|c|}
\hline \multirow{2}{*}{ Adsorventes } & \multicolumn{7}{|c|}{ Compostos sulfurados } \\
\cline { 2 - 8 } & EM & DMS & IPM & TBM & MES & SBM & THT \\
\hline \hline $\begin{array}{c}\text { Carbono ativado } \\
\text { Virgem }\end{array}$ & $>0,33$ & $>1,38$ & 0,63 & 0,77 & $>0,99$ & 0,96 & 2,00 \\
\hline $\begin{array}{c}\text { Carbono Ativado } \\
\text { Impregnado }\end{array}$ & $>0,45$ & $>2,05$ & 1,17 & 1,82 & $>1,97$ & 1,33 & 3,59 \\
\hline $\begin{array}{c}\text { Carbono Ativado } \\
\text { Oxidado }\end{array}$ & $>0,42$ & $>1,75$ & 0,89 & 0,96 & $>1,69$ & 1,01 & 2,99 \\
\hline
\end{tabular}

Legenda: EM - Etilmercaptana, DMS - Dimetilsulfeto, IPM - Isopropilmercaptana, TBM -Tercbutilmercaptana, MES - Metiletilsulfeto, SBM - Sec-butilmercaptana e THT - Tetrahidrotiofeno

Mesmo que diferentes massas de cada composto de enxofre sejam adsorvidas, nota-se que as capacidades de adsorção aumentaram na seguinte ordem: EM $<$ IPM $<$ TBM $<$ SBM $<$ MES < DMS < THT para todos os adsorventes. A adsorção deu-se preferencialmente para os sulfetos e logo depois para as mercaptanas segundo o maior peso molecular dos compostos, visto que, são adsorvidos mais facilmente pelo carbono ativado (Srivastava et al., 2009). Além disso, os grupos superficiais presentes no carbono ativado são responsáveis por oxidar os compostos de enxofre a sulfóxidos ou sulfonas pela adição de um ou dois átomos de oxigênio ao enxofre, respectivamente. Os sulfetos são oxidados mais rapidamente pelo fato das mercaptanas precisarem ser primeiro oxidadas a sulfetos e/ou dissulfetos para depois chegarem a sulfóxidos e sulfonas. Tendo em vista o maior peso molecular e polaridade, esses compostos são adsorvidos com maior facilidade (Ali et al., 2009).

Os diferentes pontos de ruptura também revelam a diferente afinidade que a superfície do carbono tem com cada composto de enxofre. Outros fatores como, as características químicas das superfícies dos adsorventes e as estruturas químicas dos compostos de enxofre estão diretamente relacionadas à seletividade de adsorção (Zhou et al., 2009). De acordo com Cui e colaboradores (2008) as modificações realizadas produzem um grande número de grupos ácidos na superfície do carbono ativado, principalmente, o ácido carboxílico, anidridos, lactonas e grupos fenóis, onde o oxigênio presente em alguns grupos tem maior seletividade para determinados compostos em relação a outros.

As duas modificações melhoram a capacidade de adsorção para os sete compostos de enxofre, mesmo a área superficial sendo menor (dados da Tabela 1). Como as alterações no volume e diâmetro dos poros após a modificação não foram expressivas pode-se intuir que as novas propriedades químicas produzidas se sobrepõem as propriedades físicas, como a área superficial, sendo assim possível aumentar as massas adsorvidas para todos os compostos. Segundo Bandosz (2002) os grupos superficiais atuam como catalisadores, oxidando moléculas orgânicas e inorgânicas, facilitando assim a adsorção nos microporos. Os carbonos ativados são bastante aplicados em processos de dessulfurização por adsorção, porém novos adsorventes como a bentonita possuem um grande potencial devido as suas propriedades químicas de superfície. 


\section{CONCLUSÃO}

Resultados melhores para a capacidade de remoção de enxofre foram obtidos com ambos os carbonos ativados modificados, por impregnação e oxidação, quando comparados ao adsorvente virgem. Sendo que o carbono ativado impregnado com cloreto de ferro III apresenta uma maior capacidade de adsorção em relação ao carbono ativado oxidado com ácido nítrico.

\section{REFERÊNCIAS BIBLIOGRÁFICAS}

ALI, M. F.; AL-MALKI, A.; AHMED, S. Chemical desulfurization of petroleum fractions for ultra-low sulfur fuels. Fuel Processing Technology, v. 90, n. 4, p. 536- 544, 2009

AKSU, Z.; ÇAĞATAY, S. S.; GÖNEN, F. Continuous fixed bed biosorption of reactive dyes by dried Rhizopus arrhizus: Determination of column capacity. Journal of Hazardous Materials, v. 143, n. 1-2, p. 362-371, 2007.

BANDOSZ, T. J. On the Adsorption/Oxidation of Hydrogen Sulfide on Activated Carbons at Ambient Temperatures. Journal of Colloid and Interface Science, v. 246, p. 1-20, 2002.

COONEY, D.O. Adsorption Design for Wastewater Treatment. Editora CRC Press, Boca Raton, Florida, 1999.

CUI, H.; TURN, S. Q. Adsorption/desorption of dimethylsulfide on activated carbon modified with iron chloride. Applied Catalysis B Environmental, v. 88, p. 25-31, 2009.

CUI, H.; TURN, S. Q.; REESE, M. A. Removal of sulfur compounds from utility pipelined synthetic natural gas using modified activated carbons. Catalysis Today, v. 139, p. 274279, 2008.

MALVESTI, A. L.; MIGNONI, M. L.; SCHERER, R. P.; PENHA G. F.; PERGHER, S. B. C. Estudo da adsorção de compostos sulfurados empregando zeólitas contendo zinco. Química Nova, v. 32, n. 6, p. 1491-1494, 2009.

QIU J., NING P., WANG X., LI K., LIU W., CHEN C., WANG L. Removing carbonyl sulfide with metal-modified activated carbon. Frontiers of Environmental Science \& Engineering, v. 10, p. 11-18, 2016.

RUTHVEN, D. M. Principles of Adsorption and Adsorption Processes. John Wiley \& Sons: New York, 1984

SRIVASTAVA, V. C.; MALL, I. D.; MISHRA, I. M. Competitive adsorption of cadmium (II) and nickel (II) metal ions from aqueous solution onto rice husk ash. Chemical Engineering and Processing: Process Intensification, v. 48, n. 1, p. 370- 379, 2009.

ZHOU, A.; MA, X.; SONG, C. Effects of oxidative modification of carbon surface on the adsorption of sulfur compounds in diesel fuel. Applied Catalysis B: Environmental, v. 87, n. 3-4, p. 190-199, 2009. 